\title{
Simulation of the dynamic behaviour of steam turbines with Modelica
}

\author{
Juergen Birnbaum ${ }^{\mathrm{a}}$, Markus Joecker ${ }^{\mathrm{b}}$, Kilian Link ${ }^{\mathrm{a}}$, Robert Pitz-Paal ${ }^{\mathrm{c}}$, Franziska Toni ${ }^{\mathrm{a}}$, Gerta \\ Zimmer $^{\mathrm{d}}$ \\ ${ }^{a}$ Siemens AG, Energy Sector, Erlangen, Germany \\ ${ }^{\mathrm{b}}$ Siemens AG, Energy Sector, Finspång, Sweden \\ ${ }^{c}$ German Aerospace Center, Institute of Technical Thermodynamics, Cologne, Germany \\ ${ }^{\mathrm{d}}$ Siemens AG, Energy Sector, Muelheim, Germany \\ juergen.jb.birnbaum@siemens.com, markus.joecker@siemens.com, kilian.link@ siemens.com, \\ robert.pitz-paal@dlr.de, franziska.toni@cbi.uni-erlangen.de, gerta.zimmer@ siemens.com
}

\begin{abstract}
Steam turbine technology is one of the leading technologies used in electricity production since more than one hundred years. In recent time requirements for steam turbines have been changing slowly. Steam turbines are not longer used in power plants with high operation times and a high full load share only, but are also implemented in combined cycle power plants or solar thermal power plants. This type of plants requires good dynamic behavior of the steam turbine due to fast and frequent start ups and daily cycling.
\end{abstract}

To optimize the performance of this kind of power plants and their components it is necessary to simulate and analyze their dynamic behavior. Therefore, a general model approach for steam turbines within Modelica has been developed. This model approach is based on a general model, which can be adjusted to the necessary model depth as described in this paper.

Steam turbines in a solar thermal power plant with direct steam generation must fulfill special requirements regarding their dynamic behavior. Hence, this model is applied as an example to explain the behavior of an industrial steam turbine used in such plants. Furthermore, this paper shows first results of simulations with turbine models. To validate the model, the results are compared with results from the Siemens internal steady state calculation tool. Since results stay within the estimated accuracy, the model approach can be used for further calculations.

The dynamic behavior of the turbine is analyzed by using typical solar irradiance disturbances. This analysis shows that no critical operation points occur within the turbine.

Keywords: solar thermal power plant, dynamic turbine behavior, turbine modeling

\section{Introduction}

Steam turbines are typically used in different types of power plants (e.g. fossil fired steam power plants, nuclear power plants, combined cycle power plants, solar thermal or biomass power plants) with different requirements regarding their dynamic behavior.

Generally, a fossil fired steam power plant is operating more than $7000 \mathrm{~h}$ a year with the rated power output. Therefore, the dynamic behavior of the steam turbine is not essential for this kind of plants. Combined cycle power plants normally operate in middle load, hence the dynamic behavior of the steam turbine is of main importance for the start-up procedure. This aspect gained even more significance since, due to the new grid requirements arising from renewable electricity generation, combined cycle power plants are also used for peak load supply.

The value of the dynamic behavior of steam turbines in a solar thermal power plant has been even rising, since daily cycling, fast start-up behavior and good transient behavior have become essential requirements. The dynamic behavior of the solar field and of the power block, especially the steam turbine and their interaction to bring solar thermal power plants with direct steam generation into the market, are questions still to be answered. As an appropriate solution, the layout of such a plant has been analyzed and optimized in a first step as described in [1] and [2]. Further steps will be a dynamic analysis of the solar field, of the turbine itself and their interactions. Parts of this analysis are already done and described in [3]. This paper addresses the modeling of such a steam turbine and provides a first analysis of its dynamic behavior. 


\section{Plant configuration}

The basic layout of the analyzed solar thermal power plant with direct steam generation is shown in figure 1. It consists of a solar field, the power block based on a Rankine-cycle and an optional thermal storage system.

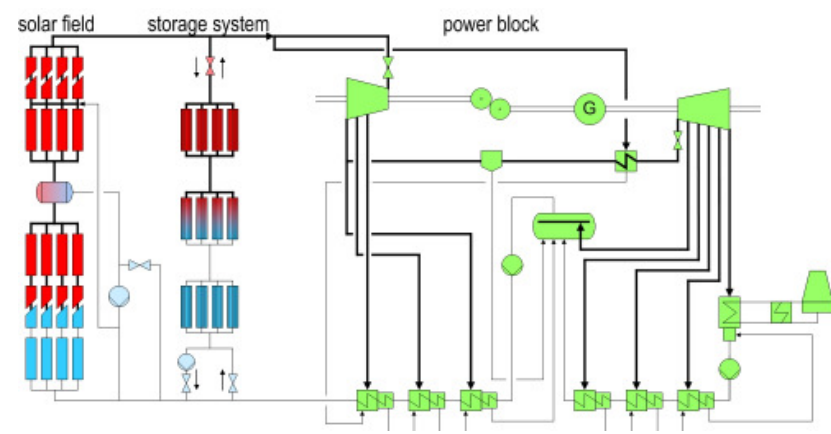

figure 1: $50 \mathrm{MW}_{\text {el }}$ parabolic trough power plant with direct steam generation

During the ITES project different power plant configurations have been designed [2]. One of these configurations, a plant layout for $50 \mathrm{MW}_{\mathrm{el}}$ with main steam parameters of $500^{\circ} \mathrm{C}$ and $110 \mathrm{bar}$, has been chosen for the modeling of the steam turbine and the analysis of its dynamic behavior.

The solar field is divided into four subfields, each with an evaporator and a superheater section, and is operated in recirculation mode. [1] provides a detailed description of the solar field layout. The power block contains a steam turbine, which is divided into a Hp- and a Lp- turbine, a feed water preheater section with six preheaters, the feed water pumps, the feed water tank and a wet cooling tower. The steam between the turbines is reheated again through a steam-steam reheater with condensation. This study does not focus on the optional thermal storage system which will, therefore, not be explained within this paper.

\section{Modeling}

A general model has been developed to show the dynamic behavior of a "solar" steam turbine. This general model can be adjusted to different turbine types and the necessary model depth. In this example, the "solar" steam turbine for the above described plant layout is modeled within Modelica. The validation of the model approach is done through a comparison of the simulation results of this model with results from stationary calculations by a Siemens inhouse tool.

\subsection{Modeling approach}

Steam turbines consist of different components, which are casing and shaft with the blading. Depending on the question to answer, the steam turbine has to be modeled with a certain level of detail. Therefore, the model has been designed in a way that allows to simulate a single blading group as well as the turbine as a whole.

The basic model, shown in figure 2 , has been built-on a turbine section, an inlet and outlet volume and the flange. The masses for the casing and the shaft are considered in corresponding wall models.

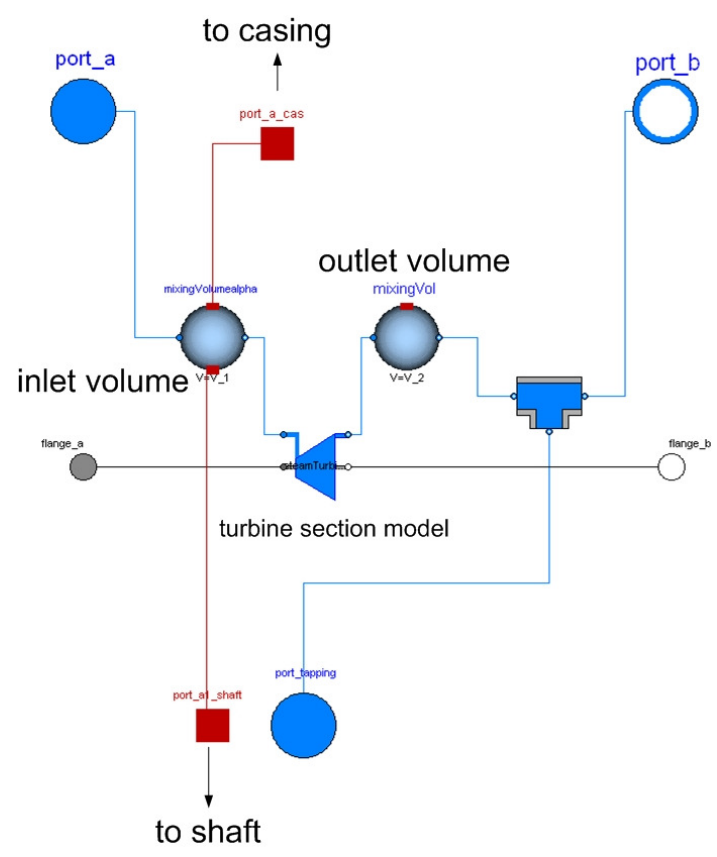

figure 2: basic steam turbine model

The mass flow through the turbine section is calculated by using Stodola's law [4]. Heat transfer between the steam and the casing respectively the shaft is calculated at the inlet volume. The level of detail for the basic model is predefined depending on the initial values for pressure and enthalpy and the geometric inputs (e.g. one basic model to model the Hpturbine).

\subsection{Modeling of a "solar" steam turbine}

Figure 1 shows a schematic drawing of a parabolic trough power plant. However, to analyze the dynamic behavior of the steam turbine, it is not necessary to simulate the whole power plant as long as reasonable data for disturbances at the boundaries is available.

Since enough data for disturbances around the "solar" turbine had been available, reasonable boundaries have been chosen (figure 3). The solar 
field input and the mass flow at the extractions have been chosen as boundary conditions for the Hpturbine. Similar boundary conditions have been selected for the Lp-turbine, where, additionally, the condenser backpressure has been selected. The mass flow at the condensate side of the reheater is suitable as reheater boundary condition.

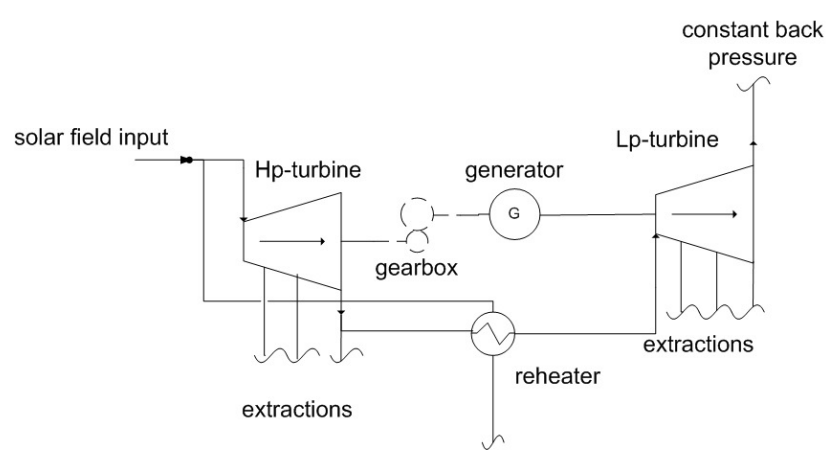

figure 3: reasonable boundaries for the turbine model

Due to the chosen boundary conditions a reasonable design for the turbine model has to be applied which is dividing each turbine into different sections. Each of these sections is described by the general model. Three sections have been selected for the Hpturbine and five sections for the Lp-turbine. Each section is defined from turbine inlet respectively turbine extraction to the following turbine extraction. Figure 4 shows the overall turbine model and the division of the Hp-turbine into the three suitable sections.

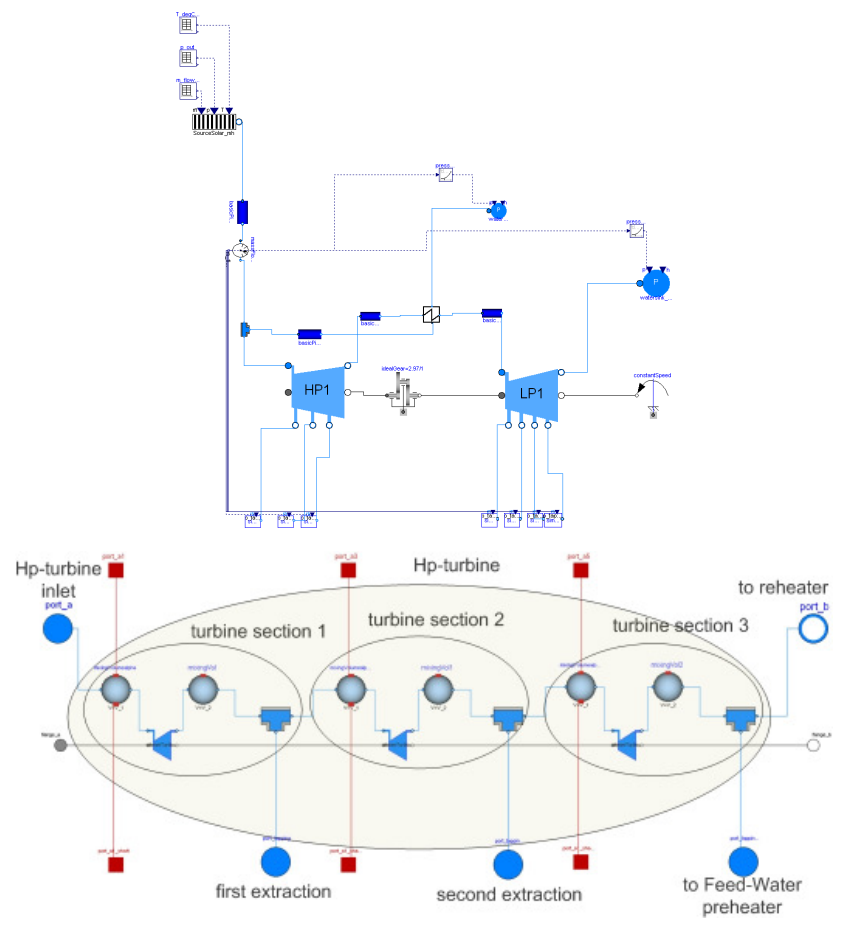

figure 4: Overall turbine model and division of the Hp-turbine into suitable turbine sections

\subsection{Validation of the model}

In order to validate this model, results of the stationary calculations by the internal Siemens tool have been recalculated with Dymola/Modelica. Typically, load cases from $100 \%$ load down to $40 \%$ load in steps of $20 \%$ are calculated for this analysis. The results for these load cases of both tools were compared at the inlet of the different turbine sections and the outlet of the Lp-turbine.

The relative failure in the calculated mass flow through each turbine section is within $+1.3 \%$ and $0.1 \%$; for the enthalpy it is within $+0.3 \%$ and $-0.2 \%$ for all calculated load cases. Regarding pressure calculation, the relative failure stays within the same range except for the Lp-turbine inlet, leading to a failure in the pressure calculation in every modeled section of the Lp-turbine. Within those, the relative failure varies over all load cases between $+6.5 \%$ and $-0.1 \%$.

This failure occurs from different calculation methods used for the calculation of the pressure loss over the reheater within the tools. In the Dymola/Modelica model the pressure loss over the reheater is calculated according to a given geometry. In contrast, within the Siemens internal calculation tool the pressure loss in part load is calculated with an approximation considering the design pressure loss, the design mass flow and the actual mass flow.

Exemplary the results for the $80 \%$ load case is shown in table 1.

table 1: Comparison of the calculation results for $80 \%$ load (turbine with reheat)

\begin{tabular}{|l|c|c|c|}
\hline rel. Failure & $\mathbf{p}$ in \% & $\mathbf{h}$ in \% & $\mathbf{~}_{\text {flow }}$ in \% \\
\hline Hp-inlet & 0.192 & 0.035 & -0.004 \\
\hline 1. extraction & 0.474 & 0.055 & 0.023 \\
\hline 2. extraction & 0.495 & 0.061 & 0.049 \\
\hline Lp-inlet & 2.225 & 0.094 & 0.434 \\
\hline 3. extraction & 5.706 & 0.292 & 0.434 \\
\hline 4. extraction & 5.953 & 0.288 & 0.459 \\
\hline 5. extraction & 6.081 & 0.273 & 0.494 \\
\hline 6. extraction & 0.486 & -0.048 & 0.559 \\
\hline Lp-outlet & -0.156 & -0.032 & 0.677 \\
\hline
\end{tabular}

A comparison of the pressure failure calculation with the failure calculations of the enthalpy and the mass flow shows a relatively high difference between the calculated pressure in Modelica and the Siemens inhouse tool. Due to this significant difference, a turbine model without reheater has been analyzed in the same way as described above. 
The relative failure of the mass flow and the enthalpy calculation were in the same range as the relative failure calculated for these properties for the turbine design that has been analyzed first. The relative failure of the pressure calculation over the Lpturbine decreased to values between $+0.1 \%$ and $-1 \%$. Hence, the different calculation methods used for pressure loss over the reheater could be determined as the cause for the relatively high failure in pressure calculation (table 2).

table 2: Comparison of the calculation results for $80 \%$ load (turbine without reheat)

\begin{tabular}{|l|c|c|c|}
\hline rel. Failure & $\mathbf{p}$ in $\%$ & $\mathbf{h}$ in \% & $\mathbf{m}_{\text {flow }}$ in \% \\
\hline Hp-inlet & 0.034 & 0.000 & 0.000 \\
\hline 1. extraction & -0.065 & -0.006 & -0.030 \\
\hline 2. extraction & -0.124 & 0.035 & -0.039 \\
\hline Lp-inlet & -0.017 & 0.027 & -0.021 \\
\hline 3. extraction & -0.092 & 0.023 & -0.025 \\
\hline 4. extraction & 0.014 & 0.022 & -0.023 \\
\hline 5. extraction & -0.067 & 0.022 & -0.017 \\
\hline 6. extraction & -0.137 & 0.022 & 0.001 \\
\hline Lp-outlet & -0.084 & 0.072 & 0.001 \\
\hline
\end{tabular}

Taking into account the different calculation methods for the pressure loss of the reheater, the comparison of results between the two calculation tools shows a very good accuracy of the results. The turbine model within Dymola/Modelica can, therefore, be used for further calculations. However, it should be kept in mind, that the pressure loss calculation of any component used within the turbine model must first be analyzed separately.

\section{Simulation of the dynamic behav- ior of a "solar" steam turbine}

The simulation of the dynamic behavior of the turbine is done for typical solar disturbances. These disturbances are resulting in main steam parameter disturbances. Within the ITES-Project, the German Aerospace Center (DLR) is simulating the dynamic behavior of the solar field for such power plants [3]. The solar field outlet data (mass flow, temperature, enthalpy), calculated by the DLR, are used as input data for a simulation of the dynamic behavior of the steam turbine. The typical disturbance used for this analysis is a step disturbance in the solar radiation from $550 \mathrm{~W} / \mathrm{m}^{2}$ down to $275 \mathrm{~W} / \mathrm{m}^{2}$ over 600 s (figure $5)$.

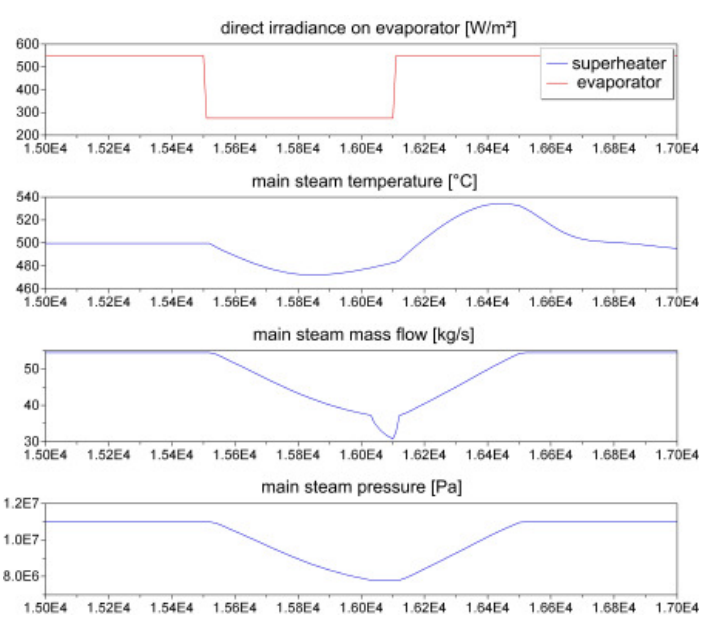

figure 5: typical irradiance disturbance and the corresponding solar field behavior

To analyze the simulated dynamic behavior of the turbine the standard specification for steam turbines IEC 60045-1 is used [5].

\subsection{Steam temperature limits}

Looking at the steam temperature behavior of the modeled Hp- and Lp-turbine sections one can clearly see that the temperature disturbance is softened over the turbine especially over the reheater (figure 6). This behavior occurrs due to the thermal inertia of the turbine and the reheater. Therefore, the steam temperature limits are analyzed only for the Hpturbine inlet, where the highest temperature stress occurs.
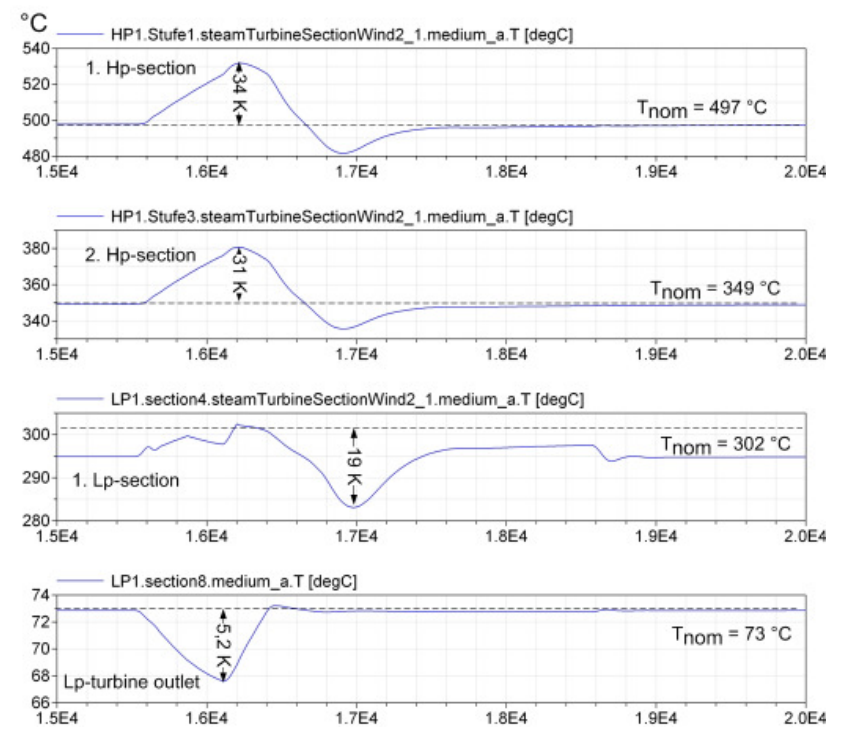

figure 6: steam temperature behavior simulated for different modeled turbine sections 


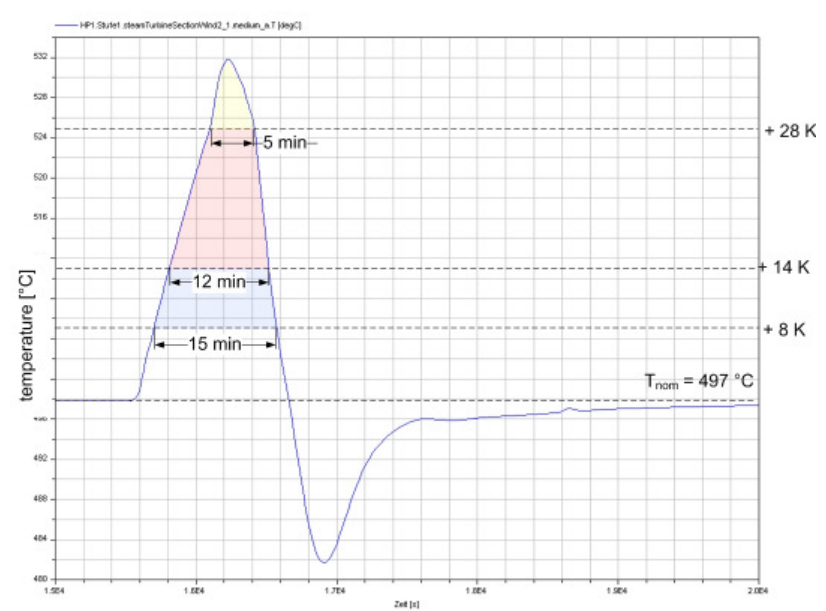

figure 7: excess steam temperature at the first modeled Hp-section

A detailed analysis at the Hp-inlet shows that temperature limits of the turbine are significantly overshot (figure 7). The temperature limits $+8 \mathrm{~K}$ and $+14 \mathrm{~K}$ over rated temperature must be analyzed on a yearly basis, as done in [3], to establish, whether the specified limits have been exceeded. The temperature limit of $+28 \mathrm{~K}$ is an absolute temperature limit. Overshooting this temperature limit will normally lead to a turbine trip influencing the steady electricity production, or reducing the expected lifetime of the turbine. As this limit has been exceeded for 5 minutes, this would already lead to a trip or significant reduction in turbine lifetime.

\subsection{Temperature differences between steam and casing respectively shaft}

Another limit of the turbine, which has to be fulfilled in operation, is the temperature difference between steam and casing respectively shaft. In case the temperature difference is exceeding a certain degree, the thermal stresses within the turbine will get too high which will lead to a reduced lifetime of the turbine.

The temperature difference between the steam and the shaft respectively casing is analyzed for the Hp-inlet (figure 8) and the Lp-inlet (figure 9). The difference between the steam temperature and the shaft temperature of the first Hp-section as well as the first Lp-section is below $0.4 \mathrm{~K}$. Like the shaft temperature, the temperature of the casing at the first $\mathrm{Hp}$-section is nearly exactly following the steam temperature. The temperature of the first Lp-section casing for the analyzed disturbance is $\sim 5.4 \mathrm{~K}$ lower than the steam temperature. The bigger mass of the Lp-casing compared to the Hp-casing and the shafts of the Hp- and Lp-turbines mainly cause this temperature difference. However, all analyzed temperature differences are well below their specified limits.

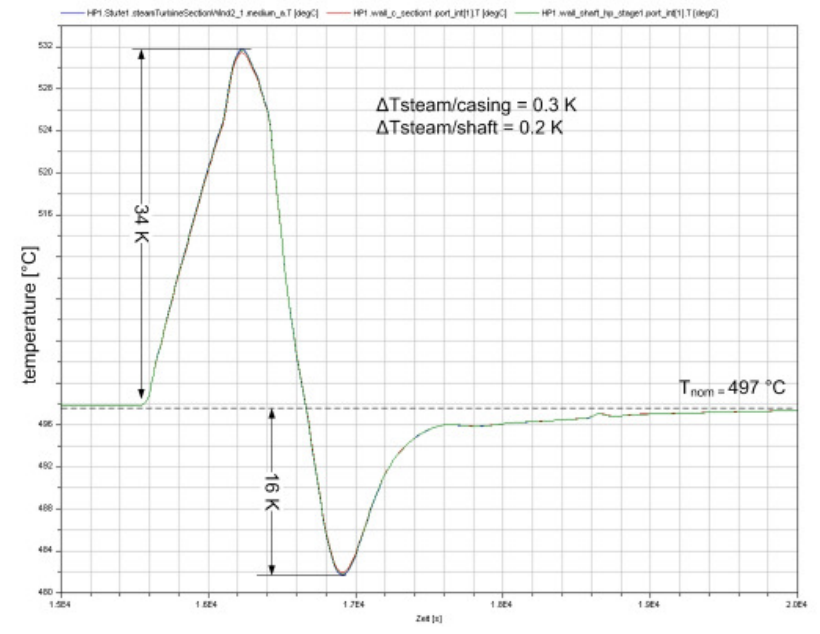

figure 8: temperature difference between steam and casing respectively shaft at first $\mathrm{Hp}$-section

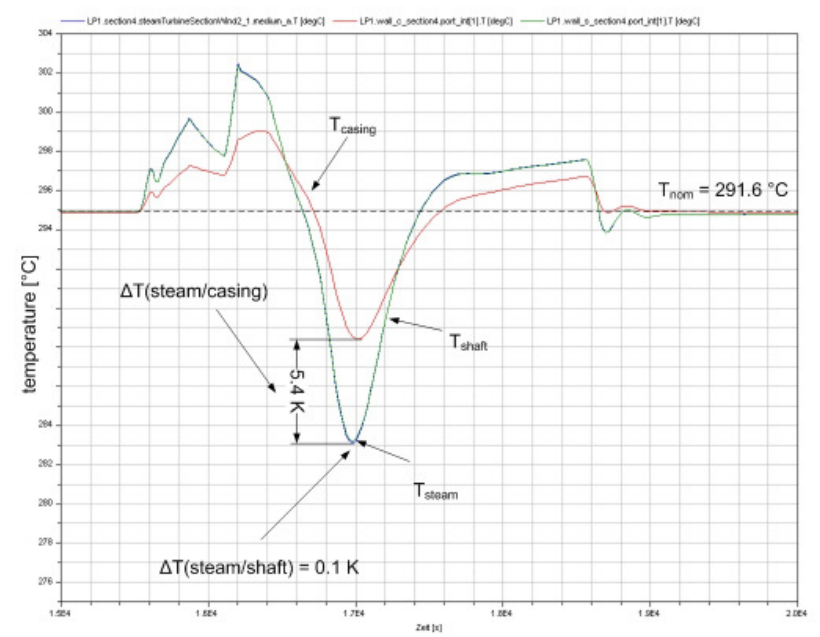

figure 9: temperature difference between steam and casing respectively shaft at first Lp-section

\subsection{Temperature distribution within the casing}

Another characteristic for the dynamic behavior of the turbine is the temperature distribution in the casing. If the temperature gradient from the inner to the outer wall of the casing is too big, the thermal stress within the casing will exceed its limits, which will again lead to a reduced lifetime of the turbine.

Since the highest temperature stress has been simulated for the first turbine section, the temperature distribution within the casing is analyzed for this section. Therefore, the casing is divided into six layers each with the same mass from the inner to the outer wall.

Figure 10 shows the maximal temperature difference of $34 \mathrm{~K}$ between the inner and the outer wall. The maximal tolerable temperature gradient, previously determined during first approximations, is $\sim 50 \mathrm{~K}$. The determined temperature gradient stays, therefore, well within these limits. 


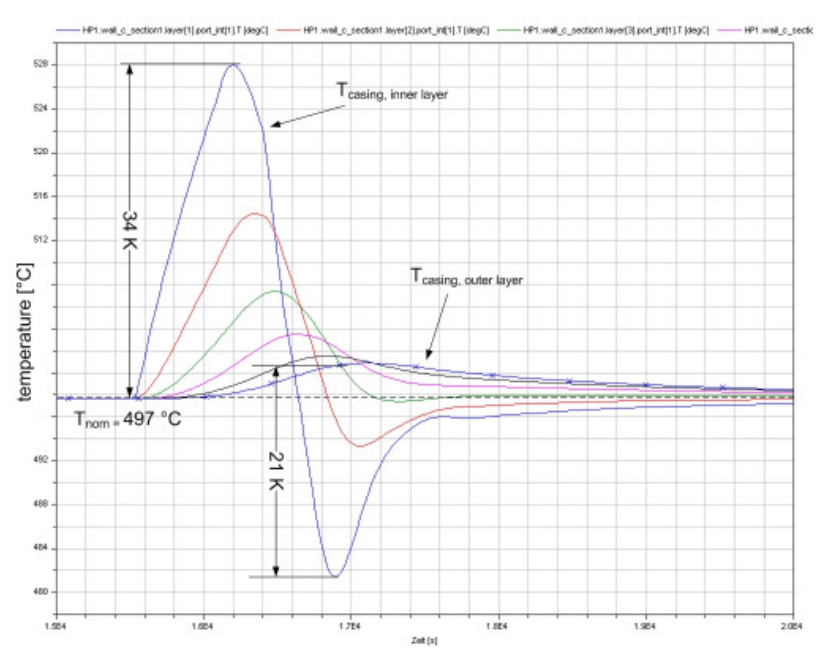

figure 10: temperature gradient within the casing of the first Hp-section (6 wall layers)

\subsection{Pressure limits}

The standard specification of the pressure disturbances for steam turbines defines only maximal pressure limits [5]. The main steam pressure for the analyzed disturbance coming from the solar field is never exceeding the rated pressure (figure 7). Since in the solar field no overpressure has been simulated it is not necessary to analyze the turbine regarding its pressure behavior.

\section{Conclusions}

This paper presents a model approach for the simulation of the dynamic behavior of steam turbines. For the purposes of an industrial steam turbine within a solar thermal power plant with direct steam generation the model approach has been compared with stationary calculations for different load points. This comparison revealed a very high accuracy of Dymola/Modelica simulations results, hence, this model can be used for further calculations.

The analysis of the dynamic behavior of the turbine within a solar thermal power plant shows that most of the typical limits for steam turbines have not been exceeded. The limit, which in fact has been exceeded, is the absolute temperature limit at the Hpturbine inlet. One possibility to control the main steam temperature within its allowed limits is to optimize the solar field control strategy. Another possibility has been evaluated within the ITES-project, where a short time storage had been integrated into the main steam path. The results of this analysis are published in [3].

\section{Acknowledgements}

The authors would like to thank the German Ministry for the Environment, Nature Conservation and $\mathrm{Nu}$ clear Safety for the financial support given to the ITES project (contract No 16UM0064).

\section{References}

[1] Birnbaum J., Eck M., et al. A Direct Steam Generation Solar Power Plant with Integrated Thermal Storage. Las Vegas, USA: 14th Bienial SolarPACES Symposium, 2008.

[2] Birnbaum J., Hirsch T., et al. A Concept for Future Parabolic Trough Based Solar Thermal Power Plants. Berlin, Germany: 15th International Conference on the Properties of Water and Steam, 2008.

[3] Birnbaum J., Feldhoff J., et al. Steam Temperature Stability in a Direct Steam Generation Solar Power Plant. Berlin, Germany: 15th Bienial SolarPACES Symposium, 2009.

[4] Traupel W. Thermische Turbomaschinen II., 3. edition. Berlin, Heidelberg, New York: Springer Verlag, 1982.

[5] International Electronic Commission (IEC) Steam turbines - Part 1: Specifications, IEC 60045-1. Geneva, 1991 